\title{
MEDLINE - International recognition of the development of Brazilian Orthodontic science
}

\begin{abstract}
Because all I need is free steps, hand in hand, and eyes wide open.
\end{abstract}
(Guimarães Rosa)

Increase in scientific production requires that periodicals be indexed in databases, in order to make information available quickly and systematically to clinical and scientific communities. The main purpose of an indexing service is to ensure prompt access to information and documents of any kind whenever one searches for a specific subject in information systems or databases.

Having a journal indexed in a database not only means merit recognition, but also corroborates the quality of published articles. Therefore, all scientific periodicals must comprise, among other features, visibility and accessibility, both of which are facilitated by indexation.

We have all witnessed the development of Brazilian Orthodontics in the last decades. We are no longer seen as mere knowledge consumers once we have become one of the countries with the greatest scientific production in Orthodontics in the world. Numerous clinical and scientific awards permeate our daily routine, ratifying our ongoing path. Despite the volcanic eruption of the specialty, our editorial production process has always been discredited. Would we be really capable of producing and maintaining an orthodontic journal with as much quality as the international periodicals used as means to ascend to our scientific success?

Dental Press Journal of Orthodontics team always believed so. We have been restlessly working for 18 years in order to achieve the same success as our Brazilian Orthodontics has achieved. Thus, we are happy to announce* that the Dental Press Journal of Orthodontics is indexed in the MEDLINE/ PubMed, the most important database providing references to health sciences information. It is a National Library of Medicine (NLM) journal citation database which has been providing over 22 million bibliographic citations since 1960. The Dental Press Journal of Orthodontics can be accessed through the following link:

http://www.ncbi.nlm.nih.gov/nlmcatalog/101532240.
Dental Press editors have known, since the publication of its first issue, in 1996, that the aim of scientific journals is to communicate and disclose scientific discussion and development, playing a leading role in breaking paradigms and being responsible for spreading knowledge about new clinical practices. This has been the case since the first publications, initially in the Journal dês Sçavans, a French journal published since 1665, and the Philosophical Transactions of the Royal Society of London, firstly published a few years later.

We must bear in mind that databases often carry out evaluations; therefore, we must keep quality standards, at risk of exclusion. Thus, to refine our criteria for manuscript acceptance and strictly monitor our ethical principles is surely an essential task. For this reason, Brazilian periodicals are little represented in international databases. It is important to highlight that only a small number of these journals have been indexed in MEDLINE/ PubMed and ISI. The indexed ones have been internationally recognized, publishing more and better articles as a reward. Additionally, science is like an iceberg of which visible portion, above the water level, represents scientific production indexed in international databases.

Hence, I sign this editorial with free steps, eyes wide open and many hands interlaced, in the attempt of expressing my gratitude to all assistant editors, former editors, authors, reviewers as well as other members of Dental Press publishing company, who have assiduously contributed not only for accomplishing the objectives of the Dental Press Journal of Orthodontics, but also for its international indexation. Undoubtedly, one more victory of Brazilian Orthodontics competency.

David Normando - editor-in-chief

(davidnormando@hotmail.com)

*I would like to thank Dental Press information analyst, Carlos Alexandre Venancio, for the text published at www.dentalpress.com.br in the event of the effective indexation of the journal in MEDLINE/PubMed. 